\title{
Contrasting heat stress response patterns of coral holobionts across the Red Sea suggest distinct mechanisms of thermal tolerance
}

\author{
Christian R. Voolstra ${ }^{1}$ (1) | Jacob J. Valenzuela ${ }^{2}$ () | Serdar Turkarslan ${ }^{2}$ | \\ Anny Cárdenas $^{1}$ (1) | Benjamin C. C. Hume ${ }^{1}$ ( ) | Gabriela Perna ${ }^{1}$ | \\ Carol Buitrago-López ${ }^{1}$ (0) | Katherine Rowe ${ }^{3}$ | Monica V. Orellana ${ }^{2,4}$ | Nitin S. Baliga ${ }^{2,5,6,7}$ \\ Suman Paranjape $^{8}$ | Guilhem Banc-Prandi, ${ }^{9,10}$ | Jessica Bellworthy, ${ }^{9,10}$ | Maoz Fine,10 | \\ Sarah Frias-Torres ${ }^{8} \odot$ | Daniel J. Barshis ${ }^{11}{ }_{\odot}$ \\ ${ }^{1}$ Department of Biology, University of Konstanz, Konstanz, Germany \\ ${ }^{2}$ Institute for Systems Biology, Seattle, USA \\ ${ }^{3}$ School of Science, The University of Waikato, Hamilton, New Zealand \\ ${ }^{4}$ Polar Science Center, University of Washington, Seattle, USA \\ ${ }^{5}$ Departments of Biology and Microbiology, University of Washington, Seattle, USA \\ ${ }^{6}$ Molecular and Cellular Biology Program, University of Washington, Seattle, USA \\ ${ }^{7}$ Lawrence Berkeley National Laboratory, Berkeley, USA \\ ${ }^{8}$ Paul G. Allen Family Foundation, Vulcan, Seattle, USA \\ ${ }^{9}$ The Interuniversity Institute for Marine Sciences (IUI), Eilat, Israel \\ ${ }^{10}$ The Goodman Faculty of Life Sciences, Bar Ilan University, Ramat-Gan, Israel \\ ${ }^{11}$ Department of Biological Sciences, Old Dominion University, Norfolk, USA
}

\section{Correspondence}

Christian R. Voolstra, Department of Biology, University of Konstanz, Konstanz 78457, Germany.

Email: christian.voolstra@uni-konstanz.de

Daniel J. Barshis, Department of Biological Sciences, Old Dominion University, Mills Godwin Building 302J, Norfolk, VA 23529, USA.

Email: dbarshis@odu.edu

Funding information

Deutsche Forschungsgemeinschaft, Grant/Award Number: 433042944 and 458901010; Paul G. Allen Family Foundation; BiNational Science Foundation grant, Grant/Award Number: 2016403; WOA Institution: UNIVERSITAET KONSTANZ; Blended DEAL: Projekt DEAL

\begin{abstract}
Corals from the northern Red Sea, in particular the Gulf of Aqaba (GoA), have exceptionally high bleaching thresholds approaching $>5^{\circ} \mathrm{C}$ above their maximum monthly mean (MMM) temperatures. These elevated thresholds are thought to be due to historical selection, as corals passed through the warmer Southern Red Sea during recolonization from the Arabian Sea. To test this hypothesis, we determined thermal tolerance thresholds of GoA versus central Red Sea (CRS) Stylophora pistillata corals using multi-temperature acute thermal stress assays to determine thermal thresholds. Relative thermal thresholds of GoA and CRS corals were indeed similar and exceptionally high $\left(\sim 7^{\circ} \mathrm{C}\right.$ above MMM). However, absolute thermal thresholds of CRS corals were on average $3^{\circ} \mathrm{C}$ above those of GoA corals. To explore the molecular underpinnings, we determined gene expression and microbiome response of the coral holobiont. Transcriptomic responses differed markedly, with a strong response
\end{abstract}


to the thermal stress in GoA corals and their symbiotic algae versus a remarkably muted response in CRS colonies. Concomitant to this, coral and algal genes showed temperature-induced expression in GoA corals, while exhibiting fixed high expression (front-loading) in CRS corals. Bacterial community composition of GoA corals changed dramatically under heat stress, whereas CRS corals displayed stable assemblages. We interpret the response of GoA corals as that of a resilient population approaching a tipping point in contrast to a pattern of consistently elevated thermal resistance in CRS corals that cannot further attune. Such response differences suggest distinct thermal tolerance mechanisms that may affect the response of coral populations to ocean warming.

\section{KEYWORDS}

CBASS coral bleaching automated stress system, coral bleaching, coral holobiont, coral metaorganism, heat stress, ocean warming, short-term acute heat stress assays, thermal resilience, thermal tolerance

\section{1 | INTRODUCTION}

Coral reefs have undergone drastic declines in recent years due to increasing anthropogenic pressure. In particular, coral bleaching, that is, the loss of Symbiodiniaceae, due to ocean warming is now among the main drivers of reef degradation (Hughes et al., 2018). Without their algal symbionts, corals lose their primary source of nutrition, often leading to widespread coral mortality. Hence, a better understanding of coral bleaching and the mechanistic underpinnings that influence susceptibility or resilience to thermal stress are of major importance.

The common notion is that corals can bleach and suffer mortality at just $1-2^{\circ} \mathrm{C}$ above their maximum monthly mean (MMM) temperatures (Glynn and D'croz L, 1990; Jokiel \& Coles, 1977, 1990), but we actually know little about empirical temperature thresholds, as most of our knowledge comes from predictive modelling, observational studies, or long-term thermal exposure experiments. Similarly, susceptibility of corals to bleaching has been attributed to genomic differences of corals and algal symbionts (Aranda et al., 2016; Barshis et al., 2013; Bhattacharya et al., 2016; DeSalvo et al., 2008, 2010; Voolstra et al., 2017), association with different microalgal symbiont species (Hume et al., 2016, 2020; Ziegler et al., 2017), or changes in the associated bacteria (Osman et al., 2020; Ziegler et al., 2017). However, it is unknown whether the same mechanisms or factors contribute to thermal tolerance of corals at large, that is, across species and sites. Corals from the Northern Red Sea, for instance, harbor exceptionally high thermal tolerance limits approaching $>5^{\circ} \mathrm{C}$ above their summer maxima, which are lethal for corals elsewhere (Evensen et al.,2021; Fine et al., 2013; Krueger et al., 2017; Osman et al., 2018; Savary et al., 2021). The Red Sea at large is one of the warmest ocean basins where corals thrive despite water surface temperatures commonly exceeding $30^{\circ} \mathrm{C}$ in the summer (Roik et al., 2016, 2018; Voolstra et al., 2020; Ziegler et al., 2019). Nevertheless, we are uncertain about the consistency of this thermal tolerance across the gradient of the Red Sea, and whether the same holobiont assemblages and molecular mechanisms are at play across different spatial scales.

Here we sought to investigate the consistency of thermal tolerance limits across spatial scales using the Coral Bleaching Automated Stress System (CBASS) (Voolstra et al., 2020) to run a series of identical short-term thermal stress assays on colonies of the coral Stylophora pistillata from three warmer central Red Sea (CRS) sites (0.3-10 km overwater distance) and a cooler Northern Red Sea site in the Gulf of Aqaba (GoA) ( 1,000 km overwater distance). Subsequent molecular examination allowed for a direct comparison of the response patterns underlying the determined temperature thresholds and revealed differences in the gene expression response and holobiont configurations that suggest distinct thermal tolerance mechanisms are at play across spatial scales. Our work demonstrates the utility of running standardized short-term heat stress assays for determination of thermal thresholds with subsequent molecular interrogation, which provide a powerful framework to identify differences in thermal tolerance response patterns and associated holobiont signatures (e.g., alleles, genes, microbes).

\section{2 | MATERIALS AND METHODS}

\section{1 | Study sites and sample collection}

In August 2018, fragments of Stylophora pistillata coral colonies were collected from one site in the northern Red Sea in the Gulf of Aqaba (GoA), the Interuniversity Institute for Marine Science (IUI) coral nursery (ICN) (N 29.50000 E $\left.34.93333^{\circ}\right)$, and three sites in the central Red Sea (CRS), Al Fahal reef (AF) (N 22.29634 ${ }^{\circ}$ E38.95914 ${ }^{\circ}$ ), the ocean-facing exposed site of Tahala reef (ExT) (N 22.26189, $\mathrm{E}$ $39.04878^{\circ}$ ), and the land-facing protected site of Tahala reef (PrT) ( $\mathrm{N} 22.26302^{\circ} \mathrm{E} 39.05165^{\circ}$ ). At each of the four sites, seven coral 
colonies were sampled, with 4 ramets collected per colony, using SCUBA at depths of 2-8 m. Colonies were sampled at least $5 \mathrm{~m}$ apart from each other to minimize the potential of sampling clonal genotypes. Sampled specimens were stored in Ziploc plastic bags upon underwater collection and transported to shore in a cooler filled with seawater where they were subjected to short-term thermal stress assays (see below). Sample collection and short-term heat stress assays for all sites were conducted within two weeks of each other (7 August for AF, 15 August for ExT and PrT, and 20 August for ICN) in parallel at the GoA ICN site, by a team of three researchers, and at the three CRS sites (AF, ExT, and PrT), by a separate team of six researchers. Every effort was made to standardize the sampling and experimental procedures, with corals at all four sites being collected the morning of the experiment day, transported to shore in seawater-filled coolers, and immediately placed in the experimental aquaria/tanks prior to starting the thermal exposures.

\section{2 | Short-term thermal stress assays}

Ramets of seven colonies (i.e., genets) of Stylophora pistillata from each of the four sites were subjected to short-term thermal stress assays. For the GoA site, experiments were run using a set of small containers with manual heating and chilling controls. For the central Red Sea sites, we employed the Coral Bleaching Automated Stress System (CBASS) (Voolstra et al., 2020). For each site, coral ramets from all seven colonies were distributed across four tanks, so that ramets from each colony (i.e., genet) were exposed to each one of four distinct temperature treatment conditions (baseline $=30^{\circ} \mathrm{C}$, medium $=33^{\circ} \mathrm{C}$, high $=36^{\circ} \mathrm{C}$, extreme $=39^{\circ} \mathrm{C}$ ), totalling 112 fragments ( 7 colonies $\times 4$ temperatures $\times 4$ sites) (Table S1). The experiments started at noon (12:00h). The four temperature treatment conditions were as follows. The baseline (control) tank was maintained at $30^{\circ} \mathrm{C}$ for the entire duration of the experiment. The other three tanks were heated to $33^{\circ} \mathrm{C}, 36^{\circ} \mathrm{C}$, and $39^{\circ} \mathrm{C}$ over a period of $3 \mathrm{~h}$. The respective temperatures were held for $3 \mathrm{~h}$, and then decreased to $30^{\circ} \mathrm{C}$ over the course of $1 \mathrm{~h}(19: 00 \mathrm{~h})$. All corals were kept at $30^{\circ} \mathrm{C}$ overnight until sampling the following morning, completing the $18 \mathrm{~h}$ short-term thermal stress assay (Voolstra et al., 2020). All tanks were continuously supplied with Red Sea seawater and light intensity was set to photosynthetic active radiation of $600 \mu \mathrm{mol}$ photons $\mathrm{m}^{-2} \mathrm{~s}^{-1}$ to match in situ light fields using a Li-Cor Li-193, spherical quantum sensor (Grottoli et al., 2021).

\subsection{Photosynthetic efficiency and visual coral bleaching assessment}

Experimental tanks were covered with a tarp at 19:00h (following the heat stress and subsequent ramping down to the control temperature) to ensure complete darkness. After $1 \mathrm{~h}$ (20:00h), we measured dark-adapted maximum quantum yield $\left(F_{v} / F_{m}\right)$ of photosystem II of all coral fragments in all temperature treatments using a pulse amplitude modulated (PAM) fluorometer (WALZ). Temperature tolerance thresholds were determined for each site as the mean (across all genets) temperature at which photosynthetic efficiency dropped to $50 \%$ of the value at baseline temperatures, defined as the Effective Dose 50 or ED50 (Evensen et al., 2021) using the DRC package in $R$ (Ritz et al., 2015). Statistical differences among site-specific ED50s were assessed via a one-way ANOVA (aov function) with individual genet ED50s as the response variable and site as the factor, with subsequent Tukey's post hoc testing via the TukeyHSD function in R. R script and data are available at GitHub (https://github.com/ reefgenomics/CBASS84/tree/master/CBASS84_PAM). For visual bleaching assessment, coral fragments were photographed before being snap-frozen in liquid nitrogen and stored at $-80^{\circ} \mathrm{C}$ until further processing (Data S1). All coral fragments showed increased paling/ whiteness at higher heat stress temperatures.

\section{4 | RNA-Seq library generation}

For nucleic acid extraction, coral tissue was sprayed off from frozen fragments using airflow from a sterile, 1,000 $\mu$ l pipette tip connected via a rubber hose to a benchtop air pressure valve and $1 \mathrm{ml}$ of ice-cold $0.22 \mu \mathrm{m}$ filtered seawater (FSW) for a maximum of $3 \mathrm{~min}$. Following this, an aliquot of $100 \mu \mathrm{l}$ of the tissue slurry was added to each of $400 \mu$ l of buffer RLT (Qiagen) and $400 \mu$ l of buffer ATL (Qiagen) for subsequent RNA and DNA isolation, respectively. Total RNA was isolated from corals exposed to $30^{\circ} \mathrm{C}, 33^{\circ} \mathrm{C}$, and $36^{\circ} \mathrm{C}$ to make a total of 84 fragments ( 7 colonies $\times 3$ temperatures $\times 4$ sites). RNA was isolated using the Qiagen RNeasy 96 kit according to the manufacturer's recommendations. Total RNA was quantified using the Qubit RNA HS Assay Kit on a Qubit 2.0 Fluorometer (Thermo Fisher Scientific) and quality-checked using the Agilent RNA 6000 Nano kit on the Agilent 2100 bioanalyzer (Agilent Technologies). RNA-Seq libraries were prepared using the TruSeq Stranded Total RNA kit (Illumina) and sequenced on eight lanes of an Illumina HiSeq 4000 using $2 \times 151$ bp paired-end reads in groups of 8-11 samples/lane. Samples from the $39^{\circ} \mathrm{C}$ heat stress were not processed, given that we observed visible tissue loss that potentially compromised sample integrity (Data S1). Samples ICN1-36, ICN3-33, ICN6-30, AF2-33, and PrT6-36 were removed from downstream analyses due to low number of sequence reads obtained (Table S2).

\section{5 | Gene expression analysis}

Paired-end Illumina reads were processed using TrimGalore version 0.4.3 (Krueger, 2012) following Illumina default quality filtering steps. Reads were further trimmed for low-quality ends (Phred score $<20$ ) and cleaned up for adapter contamination with TrimGalore. For sequence alignment, reference genomic gene sets for Stylophora pistillata (v1.0) (Voolstra et al., 2017) and Symbiodinium microadriaticum (v1.0) (Aranda et al., 2016; Nand et al., 2021) were obtained from http://spis.reefgenomics.org ( $n=25,769$ genes) and 
http://smic.reefgenomics.org ( $n=49,109$ genes), respectively (Liew et al., 2016), and gene sets were combined to create a merged reference. Transcript abundance estimation was performed by using kallisto v0.44.0 (Bray et al.,2016). Differential gene expression analysis was performed using DESeq2 package v1.22.2 (Love et al., 2014) in R after importing kallisto transcript abundance estimates with the tximport package v1.14.2 (Soneson et al., 2015) and separating S. pistillata and S. microadriaticum reads prior to DESeq2 analysis. To account for large dispersion with low read counts and create more accurate log2 fold change (LFC) estimates, the IfcShrink function for shrinking LFC estimates was applied. Transcripts with s-values (Stephens, 2017) smaller than 0.005 were defined as significantly differentially expressed (Data S2). In addition, transcript quantifications in transcripts per million (TPM) were obtained using kallisto v0.44.0 (Bray et al., 2016) (Data S2).

The analysis workflow, implemented as custom python and $\mathrm{R}$ scripts, is available at GitHub (https://github.com/reefgenomi cs/CBASS84/tree/master/CBASS84_RNASeq). Sequence data determined in this study are available under NCBI BioProject PRJNA681108 (https://www.ncbi.nlm.nih.gov/bioproject/PRJNA 681108). To determine front- and back-loaded gene candidates (sensu Barshis et al., 2013), we filtered for genes that were at least four-fold differentially expressed at $30^{\circ} \mathrm{C}$ between ICN and AF corals or their algal symbionts and that had expression values above an accumulative sum of 30 (TPM). This subset of genes was further selected for those that showed significant differential expression between $30^{\circ} \mathrm{C}$ and $33^{\circ} \mathrm{C}$ and between $30^{\circ} \mathrm{C}$ and $36^{\circ} \mathrm{C}$ in ICN or AF corals and their algal symbionts, respectively (Data S3). We also conducted the aforementioned analyses between corals from the ExT and PrT sites to test for regional front-/back-loading. Moreover, we identified the most variably expressed genes across all temperatures and reef sites to elucidate the cohort of genes that are most responsive to thermal stress (Data S3). Gene ontology (GO) enrichment analysis was done based on genomic gene set annotations available from http://reefgenomics.org and performed using the topGO package v2.42.0 (Alexa \& Rahnenfuhrer, 2018) in R with a recommended cutoff of $p<.001$ (Data S3).

\section{6 | Coral host single nucleotide polymorphism (SNP) analysis}

In order to confirm the uniqueness of sampled colonies (i.e., that they were true genets vs. clonal ramets) and to understand expression variation associated with genotypes and populations, SNPs for the different samples were determined based on the coral host RNA-Seq data. Raw RNA-Seq reads were mapped with STAR 2.5.3a (Dobin et al., 2013) with a single pass. BAM files were used for calling SNPs with the bcftools mpileup and call functions from SAMtools 1.8 (Li et al., 2009). Bcftools call was used with the arguments filter -s LowQual -e "QUAL<30 || DP>100" to create a single, merged vcf file for all SNPs and all samples excluding alignments with low mapping quality ( $<30$ mapping quality) and higher than expected coverage
(DP $>100)$. This file was then further filtered using VCFtools 0.1.16 (Danecek et al., 2011) and the following options: --max-missing 0.5 --mac 3 --minQ 30 --minDP 10 --max-alleles 2 --maf 0.015 --remove-indels. Five low coverage individuals that were removed from the differential expression analyses were then removed from the vcf file and the remaining SNPs were further filtered using the --max-missing 0.95 parameter to include only SNPs that had quality calls in at least $95 \%$ of the remaining 79 individuals (Table S2). This final filtered vcf file was then converted into genepop format with a custom python script and imported into the adegenet package (Jombart, 2008) in the R environment for principal component analysis (PCA) and plotting. Pairwise allelic distances (Hamming's distance) were calculated using the poppr package (Kamvar et al., 2014) and subsequently plotted using the hclust function in R (Aichelman \& Barshis, 2020). Documentation and scripts used to conduct the analysis are available at GitHub (https://github.com/reefgenomics/ CBASS84/tree/master/CBASS84_SNPs).

\section{7 | Symbiodiniaceae ITS2 and bacterial 16S marker gene library generation}

DNA isolation was performed using the Qiagen DNeasy 96 Blood $\&$ Tissue kit (Qiagen) following the manufacturer's instructions with minor adjustments. Briefly, coral tissue samples aliquoted for DNA isolation (see above) were thawed and equilibrated to room temperature. The slurry was vortexed and $180 \mu \mathrm{l}$ of each sample were transferred to a microtube with $20 \mu$ of proteinase $K$ for incubation at $56^{\circ} \mathrm{C}$ for $1 \mathrm{~h}$. DNA extractions were then continued according to the manufacturer's instructions. In addition to the coral samples selected for $16 \mathrm{~S}$ marker gene sequencing, three negative controls testing for "contaminants" from (i) the FSW used for spraying off the coral tissue, (ii) the DNA extraction procedure, and (iii) PCR consumables were included to account for putative laboratory and kit contaminants introduced during sample preparation. DNA concentrations were quantified by Qubit dsDNA High Sensitivity Assay Kit (Invitrogen). ITS2 (Symbiodiniaceae) and 16S (bacteria) amplicon libraries were prepared for sequencing on the Illumina MiSeq platform. To amplify the ITS2 region, the primers SYM_VAR_5.8S2 [5 '-TCGTCGGCAGCGTCAGATGTGTATAAGAGACAGGAATTGCAGA ACTCCGTGAACC-3'] and SYM_VAR_REV [5'-GTCTCGTGGGCTCG GAGATGTGTATAAGAGACAGCGGGTTCWCTTGTYTGACTTCATG

C-3'] (Hume et al., 2013, 2015, 2018) were used (Illumina adaptor overhangs underlined). To amplify the variable regions 5 and 6 of the 16S rRNA gene, the primers 784F [5'-TCGTCGGCAGCGTCAGATG TGTATAAGAGACAGAGGATTAGATACCCTGGTA-3'] and 1061R [5'GTCTCGTGGGCTCGGAGATGTGTATAAGAGACAGCRRCACGAGC TGACGAC-3'] (Andersson et al., 2008; Bayer et al., 2013) were used (Illumina adaptor overhangs underlined). Triplicate PCRs were performed (10-50 ng of DNA from each coral sample per PCR reaction) using the Qiagen Multiplex PCR kit and a final primer concentration of $0.5 \mu \mathrm{M}$ in a reaction volume of $10 \mu \mathrm{l}$. Thermal cycling conditions for ITS2 PCR amplifications were: $95^{\circ} \mathrm{C}$ for $15 \mathrm{~min}, 30$ cycles of $95^{\circ} \mathrm{C}$ 
for $30 \mathrm{~s}, 56^{\circ} \mathrm{C}$ for $90 \mathrm{~s}$, and $72^{\circ} \mathrm{C}$ for $30 \mathrm{~s}$, followed by a final extension step of $72^{\circ} \mathrm{C}$ for $10 \mathrm{~min}$. Thermal cycling conditions for $16 \mathrm{SPCR}$ amplifications were: $95^{\circ} \mathrm{C}$ for $15 \mathrm{~min}, 27$ cycles of $95^{\circ} \mathrm{C}$ for $30 \mathrm{~s}, 55^{\circ} \mathrm{C}$ for $90 \mathrm{~s}$, and $72^{\circ} \mathrm{C}$ for $30 \mathrm{~s}$, followed by a final extension step of $72^{\circ} \mathrm{C}$ for $10 \mathrm{~min}$. After the PCRs, $5 \mu \mathrm{l}$ of the PCR products were run on a $1 \%$ agarose gel to confirm successful amplification. Triplicate PCRs for each sample were pooled, and samples were cleaned using ExoProStar 1-step (GE Healthcare). Samples were indexed using the Nextera XT Index Kit v2. Successful addition of indexes was confirmed by comparing the length of the initial PCR product to the corresponding indexed sample on a $1 \%$ agarose gel. Samples were then cleaned and normalized using the SequalPrep Normalization Plate Kit (Invitrogen). The ITS2 and 16S amplicon libraries were pooled separately ( $4 \mu \mathrm{l}$ per sample) and concentrated using a CentriVap Benchtop Vacuum Concentrator (Labconco). Quality of the libraries was assessed using the Agilent High Sensitivity DNA Kit on the Agilent 2100 Bioanalyzer (Agilent Technologies), quantification was done using the Qubit dsDNA High Sensitivity Assay Kit (Invitrogen). The ITS2 and 16S amplicon libraries were sequenced on a single MiSeq run. Libraries were pooled in a one-third ITS2 to twothirds $16 \mathrm{~S}$ ratio to achieve higher read numbers for $16 \mathrm{~S}$ amplicons. Sequencing was performed at 6 pM with $20 \%$ phiX on the Illumina MiSeq platform at $2 \times 301 \mathrm{bp}$ paired-end V3 chemistry according to the manufacturer's specifications. Sequence data determined in this study are available under NCBI BioProject PRJNA681108 (https:// www.ncbi.nlm.nih.gov/bioproject/PRJNA681108).

\section{8 | Symbiodiniaceae community analysis}

The SymPortal (https://symportal.org) analytical framework was used to analyze Symbiodiniaceae ITS2 sequence data (Hume et al. 2019). Briefly, demultiplexed and paired forward and reverse fastq. gz files outputted from the Illumina sequencing were submitted directly to SymPortal. Firstly, sequence quality control was conducted as part of the SymPortal pipeline using mothur 1.43.0 (Schloss et al., 2009), the BLAST+ suite of executables (Camacho et al., 2009), and minimum entropy decomposition (MED) (Eren et al., 2015). Then, ITS2 type profiles (representative of putative Symbiodiniaceae taxa or genotypes) were predicted and characterized by specific sets of defining intragenomic ITS2 sequence variants (DIVs). Finally, the ITS2 sequence and ITS2 type profile abundance count tables (Data S4), as well as the Bray Curtis-based between-sample and betweenITS2 type profile dissimilarities, as output by the SymPortal analysis, were directly used to plot data. Scripts used for data curation and plotting are available at GitHub (https://github.com/reefgenomics/ CBASS84/tree/master/CBASS84_ITS2).

\section{9 | Bacterial community analysis}

Sequence data fastq files were analysed in mothur 1.39.5 (Schloss et al., 2009). Briefly, remaining adaptors and primers were trimmed and read pairs were concatenated. Unique sequences were removed using split.abund, followed by alignment to the 16 rRNA SILVA database, release 132 (Quast et al., 2013). Chimeras were identified using VSEARCH and removed for subsequent analysis. Clustering was done using the OptiClust algorithm and taxonomic annotation was done using the Greengenes (release May 2013) and SILVA (release 138) 16S rRNA databases. Sequences annotated as chloroplast, mitochondria, unknown, or archaea were discarded. OTU abundance table, taxonomy, and fasta files (Data S5) generated by the make.shared, classify.otu, and get.oturep commands in mothur respectively, were used as input files for statistical analyses in R. OTUs were considered putative contaminants if the ratio of their relative abundance across all negative controls to the relative abundance across all coral samples was $>10 \%$. Barplots showing the relative abundances of the most abundant 20 families were plotted using ggplot2 v2.3.1.0 (Wickham, 2011). Ordination plots and BrayCurtis dissimilarities were calculated in Phyloseq v1.26.1 (McMurdie \& Holmes, 2013). The same analyses were carried out in ASV space with resembling results; however, due to backward compatibility to reference OTU sequences from a previous study (in particular from the genus Endozoicomonas: Neave et al., 2017a; Neave et al., 2017b), we opted for OTU-based analyses. Scripts used for data analysis and plotting are available at GitHub (https://github.com/reefgenomics/ CBASS84/tree/master/CBASS84_16S).

\section{3 | RESULTS}

\subsection{Differential thermal tolerance thresholds between corals from the northern and central Red Sea}

To assess the consistency of the exceptional thermal tolerance of corals from the Red Sea and the underlying holobiont patterns, we investigated the response to heat stress in Red Sea Stylophora pistillata corals. Using a set of small aquaria and the coral bleaching automated stress system (CBASS) (Voolstra et al., 2020), we determined thermal tolerance thresholds by running a series of identical shortterm acute heat stress assays (Voolstra et al., 2020). Thermal thresholds were calculated as the temperature point at which a loss of $50 \%$ photosynthetic efficiency was inferred, henceforth referred to as the effective dose 50 (ED50) (Evensen et al., 2021). ED50s provide an empirical, comparable, and standardized proxy for coral thermotolerance (similar to the LD50 used in toxicological studies), based on the notion that increased/decreased loss of photosynthetic efficiency with temperature reflects differences in coral bleaching susceptibility (Voolstra et al., 2020). We determined thermal thresholds at two spatial scales: large-scale ( 1,000 km overwater distance) between corals from the northern Red Sea at the IUI Coral Nursery (ICN) in the Gulf of Aqaba (GoA) and corals from the central Red Sea (CRS) at Al Fahal reef (AF) and the exposed (ExT) and protected (PrT) sites of Tahala reef, and small-scale (0.3-10 km overwater distance) between corals from the AF, ExT, and PrT CRS sites (Figure 1a). The thermal 

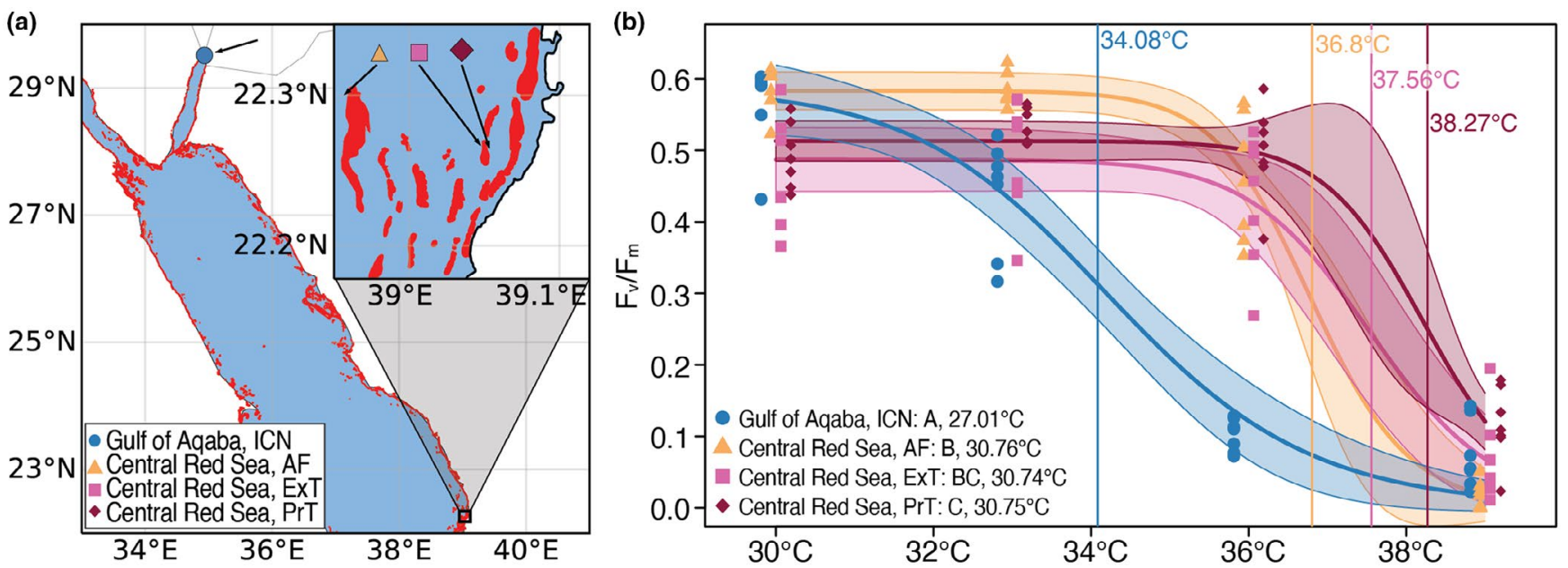

FIGURE 1 Study sites and temperature tolerance thresholds of corals from the northern and central Red Sea. (a) Map of Red Sea sites, reefs are shown in red. Seven coral colonies of S. pistillata from each of one site in the Gulf of Aqaba (ICN), northern Red Sea, and three central Red Sea sites near each other (AF, ExT, PrT) were collected and examined for heat stress response patterns. (b) Photosynthetic efficiency $\left(F_{v} / F_{m}\right)$ over temperature curves and determined ED50 thermal tolerance thresholds as a proxy for coral bleaching susceptibility (sensu Evensen et al., 2021) of corals from the ICN, AF, ExT, PrT reef sites. ED50 thermal tolerance thresholds are denoted as vertical bars with temperature values at the top of the respective bar in the respective site colour. Solid lines in each curve reflect the mean three parameter log-logistic model fit for each population ( $n=7$ colonies) with $95 \%$ confidence intervals represented by the shaded areas. Statistical differences among sites are indicated by letters in the panel legend with site-specific MMM temperatures denoted thereafter. Symbols denote measurements from individual samples. Blue circles, coral samples from the Gulf of Aqaba ICN site; yellow triangles, coral samples from the central Red Sea AF site; pink squares, coral samples from the Central Red Sea ExT site; dark red diamonds, corals from the Central Red Sea PrT site

tolerance threshold of GoA corals was significantly different from all three CRS sites (all $p<.0001$, Figure 1b). Notably, the ED50 thermal limit for GoA corals, deemed to be among the most temperature resilient corals in the world (Fine et al., 2013; Osman et al., 2018; Savary et al., 2021), was on average $>3^{\circ} \mathrm{C}$ below that of CRS corals $\left(\mathrm{ED} 50 \mathrm{GoA}=34.08^{\circ} \mathrm{C} \pm 0.30^{\circ} \mathrm{C}\right.$ vs. $\mathrm{ED} 50 \mathrm{CRS}=37.54^{\circ} \mathrm{C} \pm 0.30^{\circ} \mathrm{C}$ [mean $\pm \mathrm{SE}$ ]). However, corals from the GoA and the CRS exhibited a temperature tolerance threshold of about $+7^{\circ} \mathrm{C}$ above their regional maximum monthly mean (MMM) temperature (MMM GoA: $27.01^{\circ} \mathrm{C}$; MMM AF: $30.76^{\circ} \mathrm{C} ; \mathrm{MMM}^{\mathrm{ExT}}: 30.74^{\circ} \mathrm{C}$; MMM PrT $\left.30.75^{\circ} \mathrm{C}\right)$. Among the CRS reef sites, corals from the protected site of Tahala reef exhibited the highest ED50 thermal threshold (ED50 PrT $38.27^{\circ} \mathrm{C}$ vs. ED50 ExT $37.56^{\circ} \mathrm{C}$ vs. ED50 AF $36.80^{\circ} \mathrm{C}$ ) and were significantly different from corals at the AF site ( $p<.05$, Figure 1 b). Apart from the differences in ED50 thermal thresholds, and conversely, the similarities found with respect to relative thermal limits, the distinct shapes of the temperature response curves of corals from the GoA and CRS are noteworthy (Figure 1b). While GoA corals exhibit a continuous loss over increasing temperatures (Figure $1 \mathrm{~b}$ blue curve), all CRS corals retained their $F_{v} / F_{m}$ values up to a critical threshold above which they dropped drastically (Figure 1b yellow, pink, red curves).

\section{2 | RNA-Seq yields and genotype analysis}

We subjected coral samples from seven colonies exposed to three temperatures $\left(30^{\circ} \mathrm{C}, 33^{\circ} \mathrm{C}, 36^{\circ} \mathrm{C}\right)$ from four sites (ICN, AF, ExT, PrT) to RNA-Seq. The average number of sequenced read pairs across all samples used for the analyses was 34,512,756 (Table S2). Following adapter trimming and quality filtering, on average 9,666,810 read pairs (i.e., 19.3 mio. sequence reads) mapped to the genes of the coral S. pistillata and 6,451,749 read pairs (i.e., 12.9 mio. sequence reads) mapped to the genes of the algal symbiont $S$. microadriaticum. While mapped read coverage for S. pistillata was rather even across samples and sites, we found a lower mapping efficiency for S. microadriaticum samples from the ICN site (Figure S1), further corroborating the notion of fine-scale genetic differentiation of Symbiodinium symbionts between sites, as evidenced by the ITS2 analysis (see below).

To assess the presence of clonal coral genotypes and expression variation associated with genotypes and populations, we conducted a single nucleotide polymorphism (SNP) analysis based on SNPs called from the coral host RNA-Seq data. We determined 1,807,439 raw, unfiltered SNPs, of which 36,498 were called in $95 \%$ of the 79 samples used in the RNA-Seq analysis and that also met our specific filtering criteria (see Methods). Based on a hierarchical clustering dendrogram of pairwise Hamming's distances (Aichelman \& Barshis, 2020), each individual colony appeared to be a unique genotype/ genet (i.e., no cross-colony clones), as indicated by the consistent clustering of within-colony samples (i.e., ramets) across temperature treatments (Figure S2). Based on a principal component analysis of these data using one sample/genotype, coral populations clustered by site with some overlap across sites (Figure S3). Interestingly, corals from the central Red Sea PrT site partially overlapped with the Gulf of Aqaba ICN site, whereas corals from thecentral Red Sea ExT and AF sites overlapped completely (Figure S3). 


\subsection{Disparate patterns of gene expression in coral hosts and algal symbionts from the Gulf of Aqaba and central Red Sea under heat stress}

To elucidate the molecular response patterns underlying the differences in temperature tolerance thresholds, we analyzed gene expression of the coral hosts and algal symbionts at the control/ baseline $\left(30^{\circ} \mathrm{C}\right)$ and at the $33^{\circ} \mathrm{C}$ and $36^{\circ} \mathrm{C}$ heat stress temperatures (i.e., seven colonies/site across four sites across three temperatures = 84 samples) (Data S2, Data S3). Coral samples from the GoA and CRS sites were separated by region. Closer inspection revealed that corals from both regions differed with regard to their response to the temperature treatments: corals from the GoA displayed discrete expression responses over temperatures, as shown by the distinct colony clustering (Figure 2a) and the high number of differentially expressed genes (DEGs) between temperature comparisons (GoA site ICN, $30^{\circ} \mathrm{C}$ vs. $33^{\circ} \mathrm{C}: 105 \mathrm{DEGs} ; 30^{\circ} \mathrm{C}$ vs. $36^{\circ} \mathrm{C}: 2,766 \mathrm{DEGs} ; 33^{\circ} \mathrm{C}$ vs. $36^{\circ} \mathrm{C}: 1,903$ DEGs; Figure 2c; Data S3). In contrast, corals from the CRS did not exhibit a clear temperature response, as indicated by the clustering of all CRS corals across temperatures (Figure 2a) and the almost complete absence of DEGs between temperatures for any of the CRS sites (CRS sites AF/ExT/PrT, $30^{\circ} \mathrm{C}$ vs. $33^{\circ} \mathrm{C}$ : 0/0/0 DEGs; $30^{\circ} \mathrm{C}$ vs. $36^{\circ} \mathrm{C}: 14 / 16 / 4$ DEGs; $33^{\circ} \mathrm{C}$ vs. $36^{\circ} \mathrm{C}: 22 / 12 / 4$ DEGs; Figure 2c; Data S3). Similarly, algal symbiont gene expression clustered foremost by region with some differentiation across temperatures for algal symbionts from GoA corals and an absence thereof in CRS corals (Figure 2b). As observed for the coral host gene expression, we found a higher number of DEGs across temperatures for $\mathrm{GoA}$ algal symbionts versus a largely mute response in CRS Symbiodiniaceae (Figure 2d; Data S3).

To further explore the pattern of gene expression responsiveness in GoA corals vs. the transcriptional stasis of CRS corals, we looked for genes that exhibited front-/back-loading, suggested as a mechanism that conveys increased thermal tolerance (Barshis et al., 2013). Characterization of DEGs that had at least four-fold higher/ lower expression at the control/baseline temperature $\left(30^{\circ} \mathrm{C}\right)$ in corals from the $\mathrm{AF}$ site in comparison to the ICN site and that also exhibited differential expression between $30^{\circ} \mathrm{C}$ and $33^{\circ} \mathrm{C}$ and between $30^{\circ} \mathrm{C}$ and $36^{\circ} \mathrm{C}$ within the ICN site were considered front-/back-loaded in CRS corals and inducible in GoA corals. We determined 26 genes exhibiting front-loading and 1 gene showing back-loading in AF corals, as well as a further 33 and 88 front- and back-loaded genes, respectively, in AF coral-associated Symbiodiniaceae (Figure 2e, Data S3). Conversely, and importantly, we could not detect any gene in GoA corals or their algal symbionts that exhibited front-loading (and only 1 gene exhibited back-loading); further, no front-/back-loaded genes were identified between PrT and ExT sites for corals and their algal symbionts. This supports the notion that only CRS corals exhibit fixed high/low expression of genes. By contrast, these genes show consecutive induction/suppression across temperatures in (a)

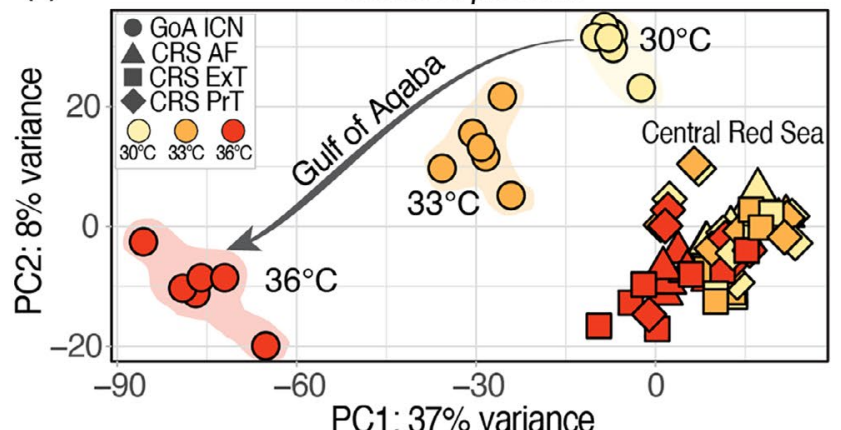

(b) Microalgal Symbiont: S. microadriaticum

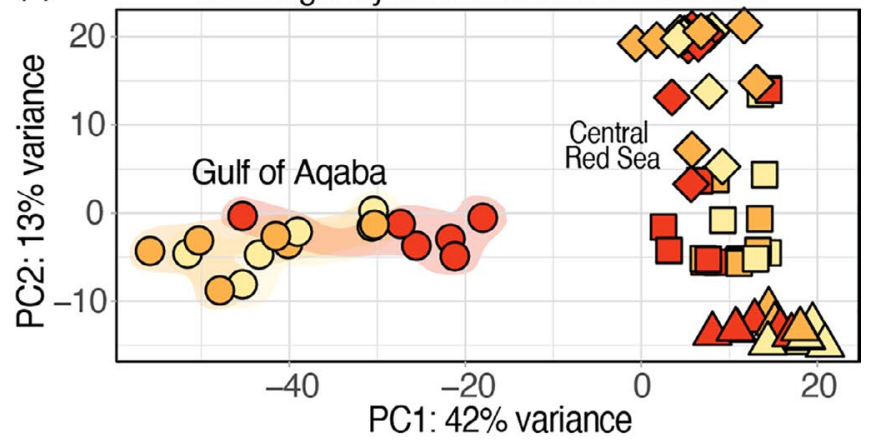

(c)

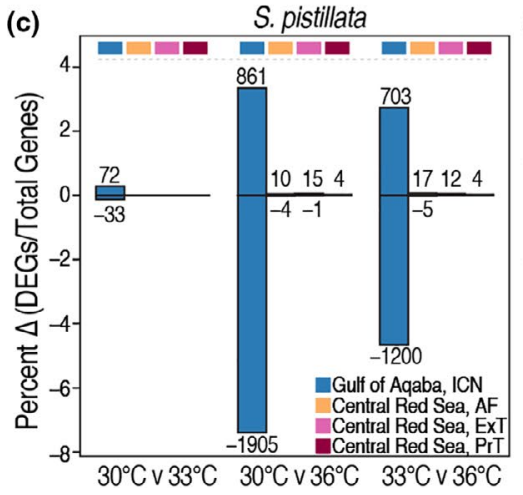

(d)

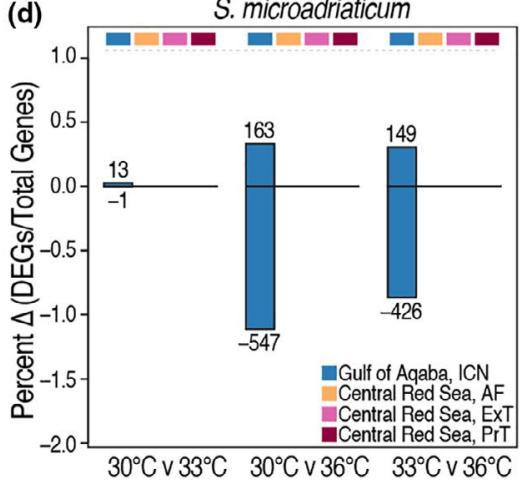

(e)

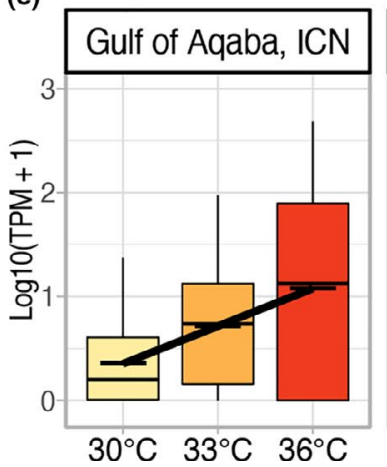

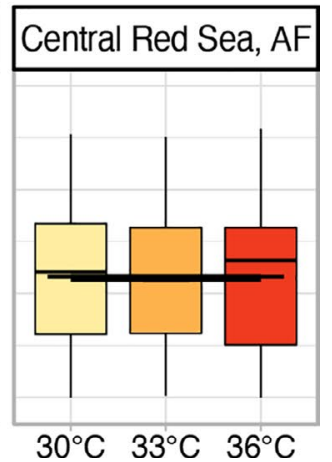

FIGURE 2 Gene expression patterns of coral hosts and algal symbionts from the northern Red Sea, Gulf of Aqaba (GoA), and central Red Sea (CRS) under heat stress. (a,b) Principal component analysis (PCA) of transcriptome-wide coral and algal symbiont gene expression. (c,d) Differentially expressed genes in coral hosts and algal symbionts for pairwise temperature comparisons of corals from the ICN, AF, ExT, PrT reef sites. (e) Gene expression front-loading (i.e., constitutive upregulation) in corals from the central Red Sea (AF reef site) versus inducible expression across temperatures in corals from the Gulf of Aqaba (ICN reef site) 
GoA corals. This, in turn, suggests distinct mechanisms of thermal tolerance in S. pistillata across Red Sea regions, that is, even for the same ocean basin and species. Conversely, mechanisms appear similar across sites within a region.

Closer examination of the front-loaded genes revealed three $S$. pistillata homologs of matrix metalloproteinases (Spis5851, Spis5854, Spis5860), further supported by GO functional enrichment analysis (GO:0004222 metalloendopeptidase activity, $p$-value=.00099), to be of functional significance (Data S3). Metalloproteinases were also previously identified among the set of front-loaded genes between temperature-tolerant and -sensitive Acropora hyacinthus in American Samoa (Barshis et al., 2013). Additionally, two Pax3 transcription factors (Spis374 and Spis375) and two homologues of TNF receptor-associated factor 3 (Spis12948 and Spis12951) putatively involved in apoptosis and activation of the immune response were identified (Häcker et al., 2011; Margue et al., 2000). The latter was confirmed by GO functional enrichment (GO:0033209 tumor necrosis factor-mediated signalling, $p$-value $=.00075$ ). Notably, we could not detect any heat shock proteins (HSPs) among the frontloaded genes, converse to what was previously found (Barshis et al., 2013). Rather, heat shock proteins (Spis4493, Spis4494, Spis4499, Spis19922, Spis19923, Spis19925) were among a list of genes that were most temperature-responsive across all sites, in line with their ubiquitous induction upon exposure to stressful conditions found across animal and plant species (Whitley et al., 1999) (Figure S4, Data S3). Among the front-loaded genes in algal symbionts, we found three genes with homology to high-affinity nitrate transporters (Smic4635, Smic4659, Smic19959) and two oxidoreductases (Smic8517, Smic40364) implicated to play a role in thermal stress susceptibility (Baumgarten et al., 2013), in addition to a suite of metabolic genes (Smic191, Smic2041, Smic32540, Smic36419) (Data S3). GO analysis could further corroborate these results, as highlighted by significant enrichments of genes associated with nitrate assimilation (GO:0042128, $p$-value $=4.2 \mathrm{E}-05$ ) and the glycolytic process (GO:0006096, $p$-value $=.00089$ ).

\subsection{Thermally stable site-specific algal symbiont communities}

We elucidated the fine-scale structure of the algal symbiont community of coral hosts from the GoA and CRS sites using the analytical framework SymPortal (Hume et al., 2019). Our analysis revealed unanimous association with microalgae of the genus Symbiodinium (LaJeunesse et al., 2018). Despite this broadscale similarity, we found fine-scale genetic differentiation of associated Symbiodinium symbionts between sites that was stable across temperatures, as evidenced by the ITS2 type profiles (Figure 3a, Data S4). Clustering by sample similarity further revealed that algal symbionts from all CRS sites were close to each other (with some outliers) and distinct from GoA algal symbionts (Figure $3 \mathrm{~b}$ ). The observed pattern of symbiont association indicates high host fidelity of algal symbionts across sites, as reported previously (Howells et al., 2020; Hume et al., 2020; Terraneo et al., 2019). Further to that, our results support fine-scale differentiation even between geographically close-by sites, as the central Red Sea sites (AF, ExT, ExP) all differed with regard to symbiont identities (Figure 3). Notably, sample dissimilarity increased with geographic distance, although the distinct clustering of some microalgal symbionts from ExT corals may suggest that divergence aligns with prevailing environmental differences, rather than geographical distance (Figure 3b).

\section{5 | Bacterial community dynamics resemble gene expression patterns of corals from the northern and central Red Sea}

Bacterial community composition ( $n=2,264$ OTUs, Data S5) profoundly changed in GoA corals in contrast to stable bacterial community association of coral colonies across temperatures for CRS sites (all $P_{\text {adj }}>0.05$, PERMANOVA, Figure $4 a$ and $c$ ). This resembles the coral host and algal symbiont gene expression patterns (a)

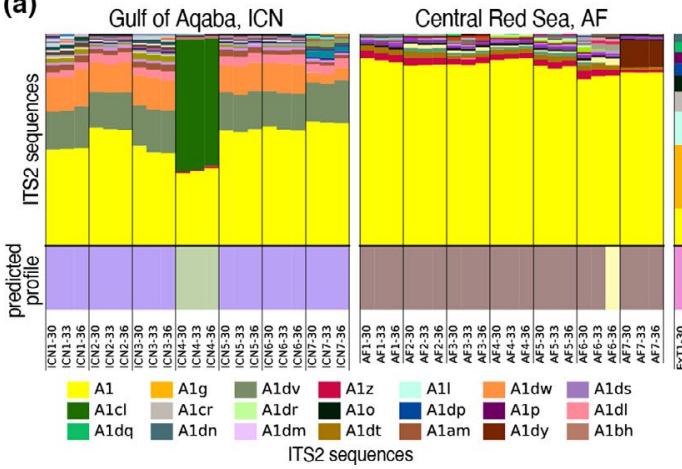

Central Red Sea, ExT

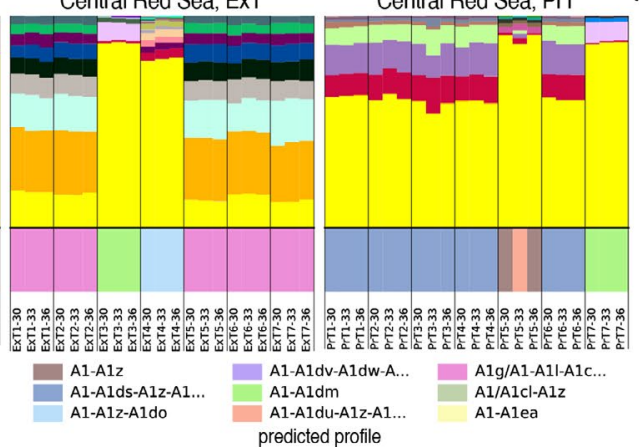

(b)

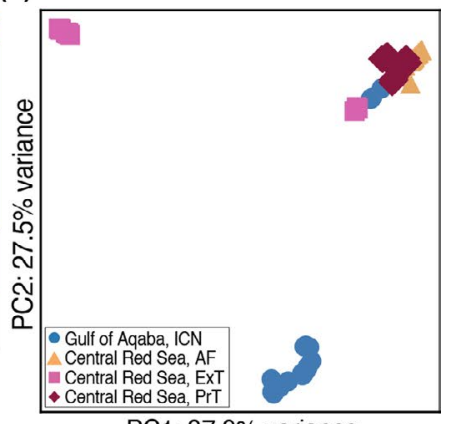

PC1: $37.9 \%$ variance

FIGURE 3 Symbiodiniaceae community composition of corals from the northern Red Sea, Gulf of Aqaba, and from the central Red Sea under heat stress. (a) Microalgal community composition across four sites sorted by coral colony ID and then heat stress temperature. Each column represents a coral colony/temperature pairing. Relative abundance of returned ITS2 sequences is plotted above the horizontal black line. Predicted ITS2 profiles are plotted below (normalized to 1). (b) Between sample dissimilarities by site. Each point represents a single coral colony/temperature pairing. Components were generated from PCoA decomposition of a Bray-Curtis computed matrix based on ITS2 sequence assemblage (Symbiodinium sequences only) 
(Figure $2 \mathrm{c}$ and $\mathrm{d}$ ), in particular with regard to a ramping response, as evidenced by the increasing number of differentially abundant bacterial taxa (OTUs) between temperature comparisons in GoA corals and absence thereof in CRS corals (Figure 4b). This notion was further confirmed statistically, in that all CRS sites were significantly different from GoA corals at all treatment temperatures with regard to coral and algal gene expression as well as bacterial community composition (all $\mathrm{P}_{\text {adj }}<0.05$, PERMANOVA, Data S2, Data S5). Among CRS sites, bacterial community composition of AF corals was significantly different from ExT and PrT sites across all temperatures $\left(\mathrm{P}_{\text {adj }}\right.$ $<0.05$, PERMANOVA), whereas the latter two resembled each other $\left(P_{\text {adj }}>0.05\right.$, PERMANOVA).

Changes in the bacterial community structure in GoA corals followed a distinct pattern over the temperature increase: only 4
OTUs (Figure $4 \mathrm{~b}$ ) were differentially abundant between $30^{\circ} \mathrm{C}$ and $33^{\circ} \mathrm{C}$ in GoA corals, whereas 80 and 42 OTUs were differentially abundant in the $30^{\circ} \mathrm{C}$ versus $36^{\circ} \mathrm{C}$ and the $33^{\circ} \mathrm{C}$ versus $36^{\circ} \mathrm{C}$ comparisons, respectively (Figure $4 \mathrm{~b}$ ). Despite the high number of differentially abundant bacterial taxa, the overall pattern was driven by a relative loss of Endozoicimonaceae (2 OTUs, mean log2 fold change $=-7.31$ ) and a relative increase of Vibrionaceae (15 OTUs, mean log2 fold change $=+9.77$ ) and Rhodobacteraceae (21 OTUs, mean log2 fold change $=+6.46$ ), suggesting dysbiosis and loss of microbiome structure (Figure 4c) (Voolstra \& Ziegler, 2020). S. pistillata colonies from CRS sites by comparison largely retained association with Endozoicimonaceae. In this context, bacteria of the genus Endozoicomonas are typically ascribed to be abundantly associated with S. pistillata in the Red Sea and globally (Bayer et al., 2013; Neave
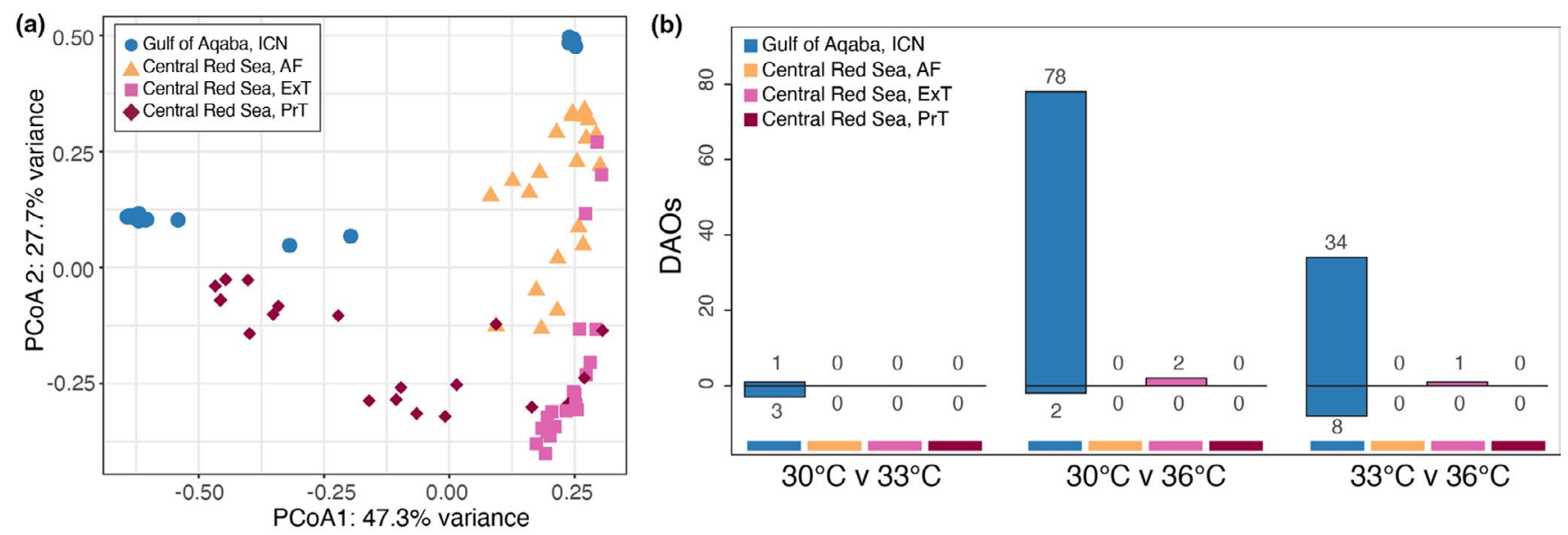

(c) ICN,Gulf of Aqaba AF, Central Red Sea
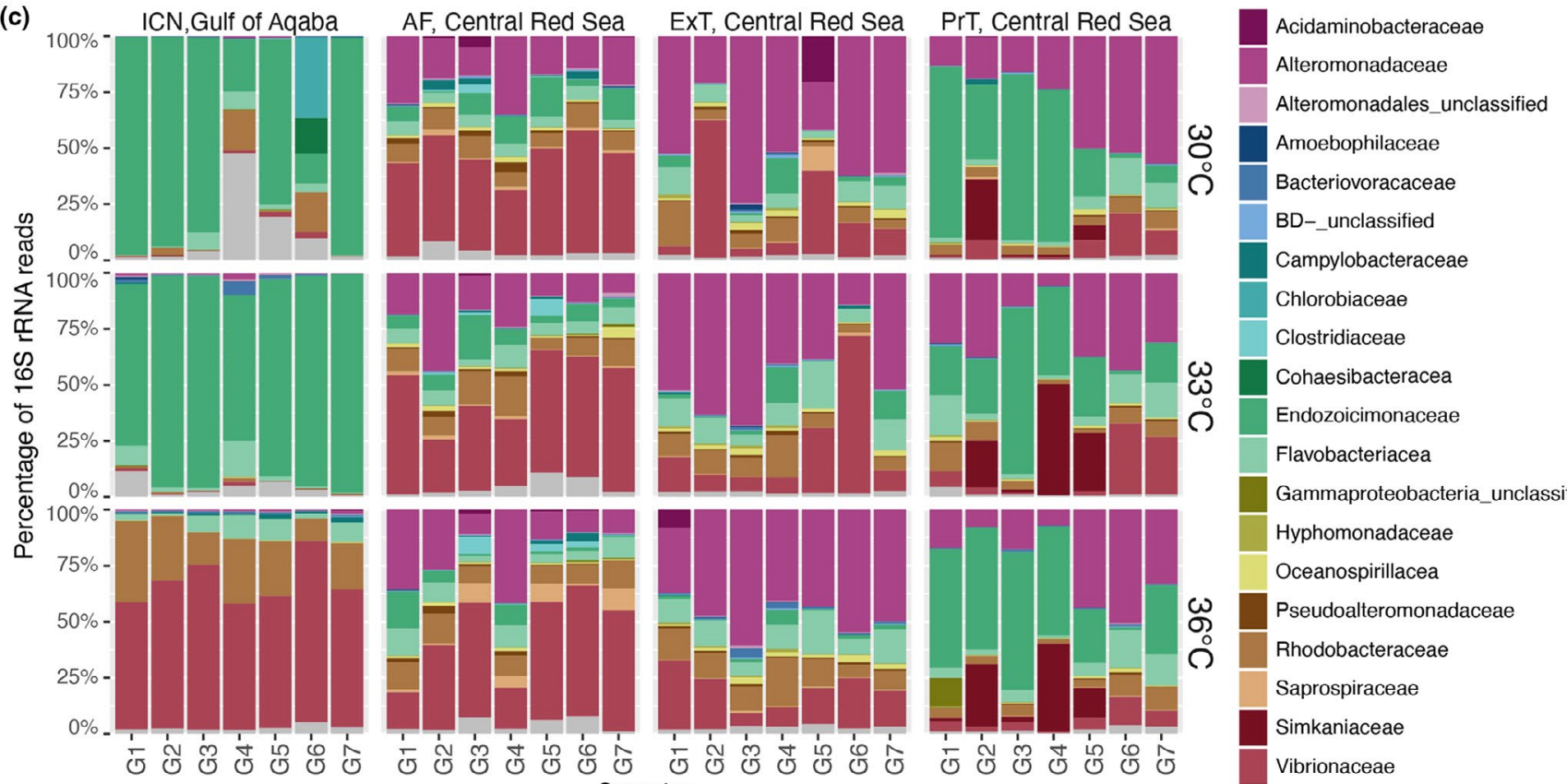

Campylobacteracea

Chlorobiaceae

Clostridiaceae

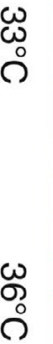

Cohaesibacteracea

Endozoicimonaceae

Flavobacteriacea

Gammaproteobacteria_unclassified
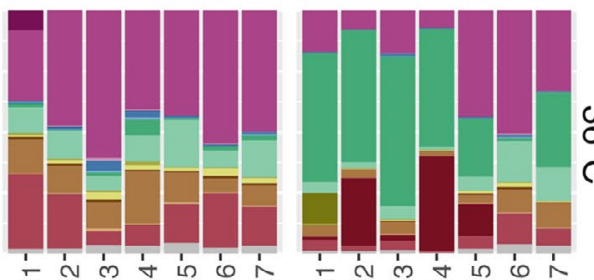

Hyphomonadaceae

Oceanospirillacea

Pseudoalteromonadaceae

Rhodobacteraceae

Saprospiraceae

Simkaniaceae

Vibrionaceae

Others Samples

FIGURE 4 Bacterial community dynamics of corals from the northern Red Sea, Gulf of Aqaba, and central Red Sea under heat stress. (a) Sample similarity based on PCoA of Bray-Curtis bacterial abundances. (b) Differentially abundant bacterial OTUs (DAOs) between pairwise temperature comparisons for experimentally examined sites. (c) OTU-based bacterial community structure across temperatures and sites on the family level. Each bar plot represents the bacterial abundance of a colony genet. The top 20 bacterial families are shown 
et al., 2017a). However, Endozoicomonas were only dominantly associated with corals from the ICN and the PrT sites, but comprised a rather small proportion of the bacterial community in corals from the AF and ExT sites (Data S5). This suggests fine-scale structuring of bacterial community composition across spatially adjacent reefs (Roder et al., 2015; Ziegler et al., 2019; Ziegler, Seneca, et al., 2017). In light of the known thermotolerance differences between the ExT and PrT reef sites (Pineda et al., 2013; Voolstra et al., 2020), it is tempting to speculate that abundance of Endozoicomonas may contribute to the observed differences in bleaching susceptibility, although prior studies found that their relative abundance was not correlated with bleaching (Pogoreutz et al., 2018; Shiu et al., 2020). Corals from the PrT site were further characterized by a relative prevalence of Simkaniaceaea, which comprise obligate intracellular bacteria of eukaryotes (Everett, 2014) and were recently shown to be a hallmark of corals from pristine environments (Ziegler et al., 2019), though their function is at present unknown. Notably, the nature of the data does not allow us to draw conclusions on bacterial biomass, that is, increase/decrease of bacterial cell densities. It is desirable to understand bacterial biomass dynamics in future experiments to better assert whether bacteria are lost from the holobiont with increasing temperature stress (similar to algal symbiont loss in bleaching) or whether we indeed observe bacterial community restructuring (Costa et al., 2021).

\section{4 | DISCUSSION}

\subsection{The need for a standardized experimental framework to further our understanding of the factors underlying coral thermal tolerance}

Despite global coral reef loss driven by ocean warming that triggers coral bleaching (Hughes et al., 2018), coral reef regions (Fine et al., 2013; Guest et al., 2012; Osman et al., 2018), populations (Barshis et al., 2013; Palumbi et al., 2014; Voolstra et al., 2020), and individual coral genotypes (Dixon et al., 2015; Palumbi et al., 2014) with enhanced bleaching resilience exist. However, a detailed understanding of the underlying factors and molecular underpinnings that drive increased thermal tolerance remains elusive. Here, we conducted identical acute thermal stress assays across four reef sites (totaling $1,000 \mathrm{~km}$ overwater distance) to assess thermal limits of corals from the northernmost Red Sea in the Gulf of Aqaba and the central Red Sea, employing a coordinated, standardized experimental framework (CBASS asssays) and subsequent molecular characterization of the coral holobiont heat stress response. Counter to previous work suggesting that the extraordinary thermal tolerance from corals of the Gulf of Aqaba might equal that of southern/central Red Sea populations (Fine et al., 2013; Osman et al., 2018), we could demonstrate that while corals throughout the Red Sea harbor consistent thermal tolerance thresholds exceeding $+7^{\circ} \mathrm{C}$ above their regional maximum monthly mean (MMM) temperature, absolute thermal limits differed according to the prevailing MMM temperature. Although it is unclear at present how ED50-derived thermal thresholds relate to natural bleaching thresholds, our determined thermal limits correspond very well with the exceptional thermal tolerance of $S$. pistillata from the Gulf of Aqaba that was found to sustain temperatures of $+5^{\circ} \mathrm{C}$ above MMM for a period of two weeks, equivalent to 9.4 DHW (Bellworthy \& Fine, 2017; Krueger et al., 2017; Savary et al., 2021). Importantly, the experimentally determined ED50 of $34.08^{\circ} \mathrm{C}$ for the $\mathrm{ICN}$ population is $3.28^{\circ} \mathrm{C}$ higher than the maximum temperature ever recorded for this site over the last decade (based on data from The Israel National Monitoring Program at the Gulf of Eilat). Irrespective of how exactly ED50s relate to DHWs (or other means of determining bleaching thresholds), our work and previous work supports the notion that higher thermal tolerance thresholds in short-term heat stress assays are representative of increased thermal stress resilience in natural settings; with ED50s serving a standardized proxy for bleaching susceptibility (Ziegler et al., 2017; Morikawa \& Palumbi, 2019; Voolstra et al., 2020; Evensen et al., 2021). Importantly, we found different thermal thresholds across different sites at both large and small scales, which were reflected by holobiont molecular response differences. This highlights the utility and potential of pairing mobile short-term heat stress assays for standardized phenotyping to detect thermal tolerance differences with subsequent investigation of the molecular response to obtain a better understanding of the factors shaping and the mechanisms underlying thermal tolerance.

\section{2 | Signatures of thermal tolerance across regions and coral holobiont compartments}

The different thermal thresholds seen in the $F_{v} / F_{m}$ data were reflected in the gene expression responses of corals and their algal symbionts as well as in the composition of the algal symbiont and bacterial communities. Transcriptional response patterns differed substantially between GoA and CRS corals with a strong response to the thermal stress in GoA corals vs. a muted/static response in CRS corals (up to 2,766 vs. up to 22 differentially expressed genes between temperature treatments in GoA and CRS corals, respectively). Notably, transcriptional differences in GoA corals were minor between the $30^{\circ} \mathrm{C}$ control and the $33^{\circ} \mathrm{C}$ heat stress temperature (105 DEGs), corroborating the notion that $33^{\circ} \mathrm{C}$ is below the critical thermal threshold of GoA corals (Bellworthy \& Fine, 2017; Evensen et al., 2021; Krueger et al., 2017). Conversely, differences were most pronounced between $30^{\circ} \mathrm{C}$ and $36^{\circ} \mathrm{C}$, but we also found substantial gene expression differences between $33^{\circ} \mathrm{C}$ and $36^{\circ} \mathrm{C}$. Overall, our data indicate the ramping up of a gene expression response with increasing heat stress in GoA corals in stark contrast to the largely muted response in CRS corals. The ramping up versus mute response of GoA vs. CRS corals is further highlighted by the presence of frontand back-loaded genes in CRS corals and the rather complete absence in GoA corals. Notably, a subset of the front-loaded genes in CRS corals were previously identified in Acropora hyacinthus corals from American Samoa (Barshis et al., 2013). On the one hand, this 
suggests the conservation of thermal tolerance genes across large geographic distances and coral species, and consequently, that universal molecular signatures of thermal tolerance exist. On the other hand, corals can show strikingly disparate heat stress response patterns, even for coral colonies/populations of the same species of the same ocean basin, indicating that distinct mechanisms of thermal tolerance exist. To further understand the dynamics of such response patterns and their utility as indicators of differential thermal tolerance, determination of expression patterns over the course of the heat stress (e.g., before, during, after heat stress, and after the recovery period) may be critical (sensu Savary et al., 2021). Similarly, reciprocal transplant or common garden follow-up experiments can further evidence whether the differences observed are genetically fixed or a consequence of acclimation (Palumbi et al., 2014; Thomas et al., 2018).

It is also striking that coral host gene expression patterns were mirrored in the algal symbiont. At large, the level of responsiveness in algal symbionts from GoA corals was unexpected, given the commonly ascribed paucity of regulation at the transcriptional level for Symbiodiniaceae (Baumgarten et al., 2013; Bayer et al., 2012), signified by fixed expression differences between symbiont genera and species (Barshis et al., 2014; Davies et al., 2018; Parkinson et al., 2016). However, the notion that algal symbionts in hospite respond transcriptionally to heat stress is now corroborated by several studies (Bellantuono et al., 2019; Fifer et al., 2021; Studivan et al., 2021) and suggest that differential gene expression analysis may provide further insight with regard to relevant cellular processes. Although we did not find direct overlap between algal symbiont front-loaded genes in comparison to another heat stress study (Fifer et al., 2021), a common denominator was that of a stress response being observed based on the functional annotation of identified genes. Hence, and unsurprisingly, differences between algal symbiont species and genotypes may exist, with putative relevance for the stress tolerance of the coral holobiont. Notably, corals from all sites associated with distinct and (largely) consistent microalgal symbiont genotypes, suggesting host fidelity and local adaptation (Howells et al., 2020; Hume et al., 2020). Despite the notion that corals from all sites harbor specific symbiont species, the consistent gene expression stasis of algal symbionts across CRS corals and the disparate responsiveness in Symbiodiniaceae from GoA corals corroborates that the geographically further apart symbionts are also genetically more differentiated.

Bacterial community composition of GoA corals changed dramatically under heat stress in contrast to CRS corals that displayed rather consistent assemblages, in support of previous work that thermally more susceptible corals have less stable microbiomes (Ziegler et al., 2017). At present, however, any presumptive functional consequences of these differences for coral holobiont physiology are largely unknown, despite it becoming broadly accepted that bacteria contribute to metaorganism biology and fitness (Bang et al., 2018; McFall-Ngai et al., 2013; Pogoreutz et al., 2020; Rosado et al., 2019; Santoro et al., 2021; Voolstra \& Ziegler, 2020; Peixoto et al., 2021). In cases of rapid environmental change, the role of the microbiome in supporting adaptation of the metaorganism may become even more pronounced, given that microbial-mediated change can be achieved through association with different microbes or exchange/incorporation of new genetic material (e.g., via horizontal gene transfer) and does not rely on adaptive evolution per se (Cárdenas et al., 2020; Voolstra \& Ziegler, 2020).

\subsection{Contrasting heat stress response patterns of coral holobionts suggest distinct mechanisms of thermal tolerance}

Our analyses indicate distinct patterns in the response to heat stress of corals from geographically distant sites in the Red Sea: corals from the GoA show dramatic changes in response to temperature across holobiont compartments versus coral-algal transcriptional and bacterial community stasis at the CRS sites. To ascertain that the observed differences between GoA and CRS corals do not align with the presence of putative cryptic lineages that would need to be considered (Burgess et al., 2021; Dziedzic et al., 2019), we conducted a preliminary population genetics analysis based on SNPs obtained from the coral RNA-Seq data. While a full-fledged population genomics analysis is beyond the scope of this study, there did appear to be greater population differentiation between corals from the ICN/PrT sites on the one hand and corals from the EXT/AF sites on the other hand based on our SNP analysis (Figure S3). This indicates that corals from the CRS sites are not uniformly differentiated from the ICN site, contrary to what would be expected if we were looking at two diverged and distinct lineages. While our analysis cannot definitely determine whether corals from the CRS and GoA represent different populations of the same lineage or multiple cryptic lineages, the overlap between some samples within the PrT population and the ICN population, suggest long-distance dispersal is putatively possible. Our results are also in line with the notion that only Stylophora pistillata clade 4 occurs in the Red Sea (sensu Keshavmurthy et al., 2013; Malik et al., 2021).

We posit that the observed response differences may be reflective of the nature of the underlying differences in thermal tolerance: we interpret the GoA coral response as that of a resilient population responding to the strength of a stressor. In contrast, the static pattern of consistently elevated but fixed expression states is suggestive of thermal resistance in CRS corals. It may be that both mechanisms evolved in their respective environments, but it is not clear whether they present different solutions to the same problem, or one may prove more successful than the other in countering future ocean warming. Intuitively, a response-resilience mechanism seems more adaptable to changing environments than a static-resistance mechanism that lets coral holobionts operate at maximum capacity irrespective of the external input, as any additional stress cannot lead to a change in response. Further insight may come from the photosynthetic efficiency response curves, which reflect the molecular patterns observed: CRS corals exhibit stable $F_{v} / F_{m}$ values over the experimental temperatures assessed 
with RNA-Seq (i.e., $30^{\circ} \mathrm{C}, 33^{\circ} \mathrm{C}, 36^{\circ} \mathrm{C}$ ). In contrast, GoA corals exhibit a slow and increasing $\mathrm{F}_{\mathrm{v}} / \mathrm{F}_{\mathrm{m}}$ loss with temperature. Pending whether such differences in mechanisms of thermal tolerance are predictive of susceptibility to future ocean warming, they may help in targeting coral colonies, species, and reefs for conservation and restoration efforts. Importantly, our work supports the existence of common gene 'signatures' (e.g., high expression of metalloproteinases under heat stress) irrespective of the underlying thermal tolerance mechanism. Such putatively universal signatures may become important in the screening for and engineering of corals with superior thermal resilience/resistance.

\section{ACKNOWLEDGEMENTS}

Research reported in this publication was supported by the Deutsche Forschungsgemeinschaft (DFG, German Research Foundation) project numbers 433042944 and 458901010 to CRV. We further acknowledge funding by the Paul G. Allen Family Foundation ("Global Search") and a BiNational Science Foundation grant (no. 2016403) to DJB and MF.

Funding Statement: Open Access funding enabled and organized by Projekt DEAL. WOA Institution: UNIVERSITAET KONSTANZ. Blended DEAL: Projekt DEAL.

\section{DATA AVAILABILITY STATEMENT}

RNA-Seq, ITS2, 16S fastq sequencing data files have been made available at NCBI under BioProject PRJNA681108 https://www.ncbi. nlm.nih.gov/bioproject/PRJNA681108. Scripts for PAM data analysis and plotting, coral host and microalgal gene expression analyses, Symbiodiniaceae and bacterial community analyses and plotting, and coral host SNP analyses can be accessed at https://github.com/reefg enomics/CBASS84. Pictures of colony fragments after short-term thermal stress are available as Supporting Information (Data S1) Gene expression estimates (TPM) for 49,109 Symbiodinium microadriaticum and 25,769 Stylophora pistillata genes, PERMANOVA statistics on pairwise comparisons between temperatures \& sites, and differentially expressed genes (DESeq) for S. pistillata and S. microadriaticum are available as Supporting Information (Data S2). Overview of differentially expressed genes, front- and back-loaded genes, GO enrichments, and heat stress response genes for $S$. pistillata and S. microadriaticum are available as supplementary data (Data S3). Symbiodiniaceae ITS2 type profiles, ITS2 sequences abundance, and ITS2 sequences are available as Supporting Information (Data S4). Bacterial 16S sequence statistics, taxa (OTUs) abundance table, and statistical analyses are available as Supporting Information (Data S5).

\section{ORCID}

Christian R. Voolstra (D) https://orcid.org/0000-0003-4555-3795 Jacob J. Valenzuela (D) https://orcid.org/0000-0002-2320-241X Anny Cárdenas (D) https://orcid.org/0000-0002-4080-9010 Benjamin C. C. Hume (D) https://orcid.org/0000-0001-7753-3903 Carol Buitrago-López (D) https://orcid.org/0000-0001-5985-5837 Sarah Frias-Torres (D) https://orcid.org/0000-0002-0557-8018 Daniel J. Barshis (D) https://orcid.org/0000-0003-1510-8375

\section{REFERENCES}

Aichelman, H. E., \& Barshis, D. J. (2020). Adaptive divergence, neutral panmixia, and algal symbiont population structure in the temperate coral Astrangia poculata along the Mid-Atlantic United States. PeerJ, 8, e10201.

Alexa, A., \& Rahnenfuhrer, J. (2018). topGO: Enrichment Analysis for Gene Ontology (R Package).

Andersson, A. F., Lindberg, M., Jakobsson, H. et al (2008). Comparative analysis of human gut microbiota by barcoded pyrosequencing. PLoS One, 3, e2836.-https://doi.org/10.1371/journal.pone.0002836

Aranda, M., Li, Y., Liew, Y. J. et al (2016). Genomes of coral dinoflagellate symbionts highlight evolutionary adaptations conducive to a symbiotic lifestyle. Scientific Reports, 6, 39734. https://doi.org/10.1038/ srep39734

Bang, C., Dagan, T., Deines, P. et al (2018). Metaorganisms in extreme environments: do microbes play a role in organismal adaptation? Zoology, 127, 1-19. https://doi.org/10.1016/j.zool.2018.02.004

Barshis, D. J., Ladner, J. T., Oliver, T. A. et al (2013). Genomic basis for coral resilience to climate change. Proceedings of the National Academy of Sciences of the United States of America, 110, 1387-1392. https://doi.org/10.1073/pnas.1210224110

Barshis, D. J., Ladner, J. T., Oliver, T. A., \& Palumbi, S. R. (2014). Lineagespecific transcriptional profiles of Symbiodinium spp. unaltered by heat stress in a coral host. Molecular Biology and Evolution, 31. 1343-1352 https://doi.org/10.1093/molbev/msu107

Baumgarten, S., Bayer, T., Aranda, M. et al (2013). Integrating microRNA and mRNA expression profiling in Symbiodinium microadriaticum, a dinoflagellate symbiont of reef-building corals. BMC Genomics, 14 , 704 https://doi.org/10.1186/1471-2164-14-704

Bayer, T., Aranda, M., Sunagawa, S. et al (2012). Symbiodinium transcriptomes: genome insights into the dinoflagellate symbionts of reefbuilding corals. PLoS One, 7, e35269 https://doi.org/10.1371/journ al.pone.0035269

Bayer, T., Neave, M. J., Alsheikh-Hussain, A. et al (2013). The microbiome of the Red Sea coral Stylophora pistillata is dominated by tissueassociated Endozoicomonas bacteria. Applied and Environmental Microbiology, 79, 4759-4762. https://doi.org/10.1128/AEM.00695-13

Bellantuono, A. J., Dougan, K. E., Granados-Cifuentes, C., \& RodriguezLanetty, M. (2019). Free-living and symbiotic lifestyles of a thermotolerant coral endosymbiont display profoundly distinct transcriptomes under both stable and heat stress conditions. Molecular Ecology, 28(24), 5265-5281. https://doi.org/10.1111/mec.15300

Bellworthy, J., \& Fine, M. (2017). Beyond peak summer temperatures, branching corals in the Gulf of Aqaba are resilient to thermal stress but sensitive to high light. Coral Reefs, 36, 1071-1082. https://doi. org/10.1007/s00338-017-1598-1

Bhattacharya, D., Agrawal, S., Aranda, M. et al (2016). Comparative genomics explains the evolutionary success of reef-forming corals. elife, 5

Bray, N., Pimentel, H., Melsted, P., \& Pachter, L. (2016). Near-optimal RNA-Seq quantification with kallisto. Nature Biotechnology, 34 525-527.

Burgess, S. C., Johnston, E. C., Wyatt, A. S. J., Leichter, J. J., \& Edmunds, P. J. (2021). Response diversity in corals: hidden differences in bleaching mortality among cryptic Pocillopora species. Ecology.

Camacho, C., Coulouris, G., Avagyan, V. et al (2009). BLAST+: architecture and applications. BMC Bioinformatics, 10, 421. https://doi. org/10.1186/1471-2105-10-421

Costa R. M., Cárdenas A., Loussert-Fonta C., Toullec G., Meibom A. Voolstra C. R. (2021). Surface Topography, Bacterial Carrying Capacity, and the Prospect of Microbiome Manipulation in the Sea Anemone Coral Model Aiptasia. Frontiers in Microbiology, 12. http:// dx.doi.org/10.3389/fmicb.2021.637834

Cárdenas, A., Ye, J., Ziegler, M. et al (2020). Coral-associated viral assemblages from the Central Red Sea Align with Host Species and 
contribute to holobiont genetic diversity. Frontiers in Microbiology, 11, 572534 https://doi.org/10.3389/fmicb.2020.572534

Danecek, P., Auton, A., Abecasis, G. et al (2011). The variant call format and VCFtools. Bioinformatics, 27, 2156-2158 https://doi. org/10.1093/bioinformatics/btr330

Davies, S. W., Ries, J. B., Marchetti, A., \& Castillo, K. D. (2018). Symbiodinium Functional Diversity in the Coral Siderastrea siderea Is Influenced by Thermal Stress and Reef Environment, but Not Ocean Acidification. Frontiers in Marine Science, 5, 150 https://doi. org/10.3389/fmars.2018.00150

DeSalvo, M. K., Sunagawa, S., Voolstra, C. R., \& Medina, M. (2010). Transcriptomic responses to heat stress and bleaching in the elkhorn coral Acropora palmata. Marine Ecology Progress Series, 402, 97-113 https://doi.org/10.3354/meps08372

DeSalvo, M. K., Voolstra, C. R., Sunagawa, S. et al (2008). Differential gene expression during thermal stress and bleaching in the Caribbean coral Montastraea faveolata. Molecular Ecology, 17, 3952-3971

Dixon, G. B., Davies, S. W., Aglyamova, G. A. et al (2015). CORAL REEFS. Genomic determinants of coral heat tolerance across latitudes. Science, 348, 1460-1462 https://doi.org/10.1126/science.1261224

Dobin, A., Davis, C. A., Schlesinger, F. et al (2013). STAR: ultrafast universal RNA-seq aligner. Bioinformatics, 29, 15-21 https://doi. org/10.1093/bioinformatics/bts635

Dziedzic, K. E., Elder, H., Tavalire, H., \& Meyer, E. (2019). Heritable variation in bleaching responses and its functional genomic basis in reef-building corals (Orbicella faveolata). Molecular Ecology, 28, 2238-2253

Eren, A. M., Morrison, H. G., Lescault, P. J. et al (2015). Minimum entropy decomposition: unsupervised oligotyping for sensitive partitioning of high-throughput marker gene sequences. The ISME Journal, 9, 968-979 https://doi.org/10.1038/ismej.2014.195

Evensen, N. R., Fine, M., Perna, G., Voolstra, C. R., \& Barshis, D. J. (2021). Remarkably high and consistent tolerance of a Red Sea coral to acute and chronic thermal stress exposures. Limnology and Oceanography https://doi.org/10.1002/Ino.11715

Everett, K. D. E. (2014). The Family Simkaniaceae. In E. Rosenberg, E. F. DeLong, S. Lory, E. Stackebrandt, \& F. Thompson (Eds.), The Prokaryotes: Other Major Lineages of Bacteria and The Archaea (pp. 891-906). Springer.

Fifer, J., Bentlage, B., Lemer, S. et al (2021). Going with the flow: How corals in high-flow environments can beat the heat. Molecular Ecology, 30, 2009-2024. https://doi.org/10.1111/mec.15869

Fine, M., Gildor, H., \& Genin, A. (2013). A coral reef refuge in the Red Sea. Global Change Biology, 19, 3640-3647. https://doi.org/10.1111/ gcb.12356

Glynn, P. W., \& D'croz, L (1990). Experimental evidence for high temperature stress as the cause of El Nino-coincident coral mortality. Coral Reefs, 8, 181-191

Grottoli, A. G., Toonen, R. J., van Woesik, R. et al (2021). Increasing comparability among coral bleaching experiments. Ecological Applications: a Publication of the Ecological Society of America, 31, e02262.

Guest, J. R., Baird, A. H., Maynard, J. A. et al (2012). Contrasting patterns of coral bleaching susceptibility in 2010 suggest an adaptive response to thermal stress. PLoS One, 7, e33353. https://doi. org/10.1371/journal.pone.0033353

Häcker, H., Tseng, P.-H., \& Karin, M. (2011). Expanding TRAF function: TRAF3 as a tri-faced immune regulator. Nature Reviews. Immunology 11, 457-468.

Howells, E. J., Bauman, A. G., Vaughan, G. O. et al (2020). Corals in the hottest reefs in the world exhibit symbiont fidelity not flexibility. Molecular Ecology, 29, 899-911. https://doi.org/10.1111/mec.15372

Hughes, T. P., Anderson, K. D., Connolly, S. R. et al (2018). Spatial and temporal patterns of mass bleaching of corals in the Anthropocene. Science, 359, 80-83. https://doi.org/10.1126/science.aan8048
Hume, B., D'Angelo, C., Burt, J. et al (2013). Corals from the Persian/ Arabian Gulf as models for thermotolerant reef-builders: prevalence of clade C3 Symbiodinium, host fluorescence and ex situ temperature tolerance. Marine Pollution Bulletin, 72, 313-322. https:// doi.org/10.1016/j.marpolbul.2012.11.032

Hume, B. C. C., D'Angelo, C., Smith, E. G. et al (2015). Symbiodinium thermophilum sp. nov., a thermotolerant symbiotic alga prevalent in corals of the world's hottest sea, the Persian/Arabian Gulf. Scientific Reports, 5(1) https://doi.org/10.1038/srep08562

Hume, B. C. C., Mejia-Restrepo, A., Voolstra, C. R., \& Berumen, M. L. (2020). Fine-scale delineation of Symbiodiniaceae genotypes on a previously bleached central Red Sea reef system demonstrates a prevalence of coral host-specific associations. Coral Reefs, 39, 583$601 \mathrm{https://doi.org/10.1007/s00338-020-01917-7}$

Hume, B. C. C., Smith, E. G., Ziegler, M. et al (2019). SymPortal: A novel analytical framework and platform for coral algal symbiont nextgeneration sequencing ITS2 profiling. Molecular Ecology Resources, $19,1063-1080$

Hume, B. C. C., Voolstra, C. R., Arif, C. et al (2016). Ancestral genetic diversity associated with the rapid spread of stress-tolerant coral symbionts in response to Holocene climate change. Proceedings of the National Academy of Sciences of the United States of America, 113, 4416-4421 https://doi.org/10.1073/pnas.1601910113

Hume, B. C. C., Ziegler, M., Poulain, J. et al (2018). An improved primer set and amplification protocol with increased specificity and sensitivity targeting the Symbiodinium ITS2 region. PeerJ, 6, e4816

Jokiel, P. L., \& Coles, S. L. (1977). Effects of temperature on the mortality and growth of Hawaiian reef corals. Marine Biology, 43, 201-208 https://doi.org/10.1007/BF00402312

Jokiel, P. L., \& Coles, S. L. (1990). Response of Hawaiian and other IndoPacific reef corals to elevated temperature. Coral Reefs, 8, 155-162 https://doi.org/10.1007/BF00265006

Jombart, T. (2008). adegenet: a R package for the multivariate analysis of genetic markers. Bioinformatics, 24, 1403-1405 https://doi. org/10.1093/bioinformatics/btn129

Kamvar, Z. N., Tabima, J. F., \& Grünwald, N. J. (2014). Poppr: an R package for genetic analysis of populations with clonal, partially clonal, and/ or sexual reproduction. PeerJ, 2, e281

Keshavmurthy, S., Yang, S.-Y., Alamaru, A. et al (2013). DNA barcoding reveals the coral "laboratory-rat", Stylophora pistillata encompasses multiple identities. Scientific Reports, 3, 1520 https://doi. org/10.1038/srep01520

Krueger, F. (2012) Trim Galore: a wrapper tool around Cutadapt and FastQC to consistently apply quality and adapter trimming to FastQ files, with some extra functionality for Mspl-digested RRBS-type (Reduced Representation Bisufite-Seq) libraries. URL http://www. bioinformatics. babraham. ac. uk/projects/trim_galore/. (Date of access: 28/04/2016)

Krueger, T., Horwitz, N., Bodin, J. et al (2017). Common reef-building coral in the Northern Red Sea resistant to elevated temperature and acidification. Royal Society Open Science, 4(5), 170038 https:// doi.org/10.1098/rsos.170038

LaJeunesse, T. C., Parkinson, J. E., Gabrielson, P. W. et al (2018). Systematic Revision of Symbiodiniaceae Highlights the Antiquity and Diversity of Coral Endosymbionts. Current Biology: CB, 28, 2570-2580, e6 https://doi.org/10.1016/j.cub.2018.07.008

Li, H., Handsaker, B., Wysoker, A. et al (2009). The Sequence Alignment/ Map format and SAMtools. Bioinformatics, 25, 2078-2079 https:// doi.org/10.1093/bioinformatics/btp352

Liew, Y. J., Aranda, M., \& Voolstra, C. R. (2016) Reefgenomics.Org - a repository for marine genomics data. Database: the journal of biological databases and curation, 2016.

Love M. I., Huber W., Anders S. (2014). Moderated estimation of fold change and dispersion for RNA-seq data with DESeq2. Genome Biology, 15(12). http://dx.doi.org/10.1186/s13059-014-0550-8 
Malik, A., Einbinder, S., Martinez, S. et al (2021). Molecular and skeletal fingerprints of scleractinian coral biomineralization: From the sea surface to mesophotic depths. Acta Biomaterialia, 120, 263-276 https://doi.org/10.1016/j.actbio.2020.01.010

Margue, C. M., Bernasconi, M., Barr, F. G., \& Schäfer, B. W. (2000). Transcriptional modulation of the anti-apoptotic protein $\mathrm{BCL}-\mathrm{XL}$ by the paired box transcription factors PAX3 and PAX3/FKHR. Oncogene, 19, 2921-2929 https://doi.org/10.1038/sj.onc.1203607

McFall-Ngai, M., Hadfield, M. G., Bosch, T. C. G. et al (2013). Animals in a bacterial world, a new imperative for the life sciences. Proceedings of the National Academy of, 110, 3229-3236 https://doi.org/10.1073/ pnas. 1218525110

McMurdie, P. J., \& Holmes, S. (2013). phyloseq: an R package for reproducible interactive analysis and graphics of microbiome census data. PLoS One, 8, e61217.

Morikawa, M. K., \& Palumbi, S. R. (2019). Using naturally occurring climate resilient corals to construct bleaching-resistant nurseries. Proceedings of the National Academy of Sciences of the United States of America, 116, 10586-10591 https://doi.org/10.1073/pnas.17214 15116

Nand, A., Zhan, Y., Salazar, O. R. et al (2021). Genetic and spatial organization of the unusual chromosomes of the dinoflagellate Symbiodinium microadriaticum. Nature Genetics, 1-12.

Neave M. J., Michell C. T., Apprill A., Voolstra C. R. (2017). Endozoicomonas genomes reveal functional adaptation and plasticity in bacterial strains symbiotically associated with diverse marine hosts. Scientific Reports, 7(1). http://dx.doi.org/10.1038/srep4 0579

Neave, M. J., Rachmawati, R., Xun, L. et al (2017). Differential specificity between closely related corals and abundant Endozoicomonas endosymbionts across global scales. The ISME Journal, 11, 186-200 https://doi.org/10.1038/ismej.2016.95

Osman, E. O., Smith, D. J., Ziegler, M. et al (2018). Thermal refugia against coral bleaching throughout the northern Red Sea. Global Change Biology, 24, e474-e484 https://doi.org/10.1111/gcb.13895

Osman, E. O., Suggett, D. J., Voolstra, C. R. et al (2020). Coral microbiome composition along the northern Red Sea suggests high plasticity of bacterial and specificity of endosymbiotic dinoflagellate communities. Microbiome, 8(1) https://doi.org/10.1186/s40168-019-0776-5

Palumbi, S. R., Barshis, D. J., Traylor-Knowles, N., \& Bay, R. A. (2014). Mechanisms of reef coral resistance to future climate change. Science, 344, 895-898 https://doi.org/10.1126/science.1251336

Parkinson, J. E., Baumgarten, S., Michell, C. T. et al (2016). Gene Expression Variation Resolves Species and Individual Strains among Coral-Associated Dinoflagellates within the Genus Symbiodinium. Genome Biology and Evolution, 8, 665-680

Peixoto R. S., Sweet M., Villela H. D. M., Cardoso P., Thomas T., Voolstra C. R., Høj L., Bourne D. G. (2021). Coral Probiotics: Premise, Promise, Prospects. Annual Review of Animal Biosciences, 9(1). 265 288. http://dx.doi.org/10.1146/annurev-animal-090120-115444

Pineda, J., Starczak, V., Tarrant, A. et al (2013). Two spatial scales in a bleaching event: Corals from the mildest and the most extreme thermal environments escape mortality. Limnology and Oceanography, 58, 1531-1545 https://doi.org/10.4319/lo.2013.58.5.1531

Pogoreutz, C., Rädecker, N., Cárdenas, A. et al (2018). Dominance of Endozoicomonas bacteria throughout coral bleaching and mortality suggests structural inflexibility of the Pocillopora verrucosa microbiome. Ecology and Evolution, 8, 2240-2252

Pogoreutz, C., Voolstra, C. R., Rädecker, N. et al (2020). The coral holobiont highlights the dependence of cnidarian animal hosts on their associated microbes. In T. C. G. Bosch, \& Hadfield MG, (Eds.), Cellular Dialogues in the Holobiont (pp. 91-118). CRC Press

Program and at the Gulf of Eilat NMP.NMP. , xxxxThe Israel National Monitoring Program at the Gulf of Eilat NMP. NMP
Quast, C., Pruesse, E., Yilmaz, P. et al (2013). The SILVA ribosomal RNA gene database project: improved data processing and web-based tools. Nucleic Acids Research, 41, D590-D596

Ritz, C., Baty, F., Streibig, J. C., \& Gerhard, D. (2015). Dose-Response Analysis Using R. Plos One, 10, e0146021 https://doi.org/10.1371/ journal.pone.0146021

Roder, C., Bayer, T., Aranda, M., Kruse, M., \& Voolstra, C. R. (2015). Microbiome structure of the fungid coral Ctenactis echinata aligns with environmental differences. Molecular Ecology, 24, 3501-3511

Roik, A., Röthig, T., Pogoreutz, C., Saderne, V., \& Voolstra, C. R. (2018). Coral reef carbonate budgets and ecological drivers in the central Red Sea - a naturally high temperature and high total alkalinity environment. Biogeosciences, 15, 6277-6296 https://doi.org/10.5194/ bg-15-6277-2018

Roik, A., Röthig, T., Roder, C. et al (2016). Year-Long Monitoring of Physico-Chemical and Biological Variables Provide a Comparative Baseline of Coral Reef Functioning in the Central Red Sea. PLoS One, 11, e0163939 https://doi.org/10.1371/journal.pone.0163939

Rosado, P. M., Leite, D. C. A., Duarte, G. A. S. et al (2019). Marine probiotics: increasing coral resistance to bleaching through microbiome manipulation. The ISME Journal, 13, 921-936 https://doi. org/10.1038/s41396-018-0323-6

Santoro, E. P., Borges, R. M., Espinoza, J. L. et al (2021). Coral microbiome manipulation elicits metabolic and genetic restructuring to mitigate heat stress and evade mortality. Science. Advances

Savary, R., Barshis, D. J., Voolstra, C. R. et al (2021). Fast and pervasive transcriptomic resilience and acclimation of extremely heat-tolerant coral holobionts from the northern Red Sea. (p. 118).Proceedings of the National Academy of Sciences of the United States of America

Schloss, P. D., Westcott, S. L., Ryabin, T. et al (2009). Introducing mothur: open-source, platform-independent, community-supported software for describing and comparing microbial communities. Applied and Environmental Microbiology, 75, 7537-7541 https://doi. org/10.1128/AEM.01541-09

Shiu, J.-H., Yu, S.-P., Fong, C.-L. et al (2020). Shifting in the Dominant Bacterial Group Endozoicomonas Is Independent of the Dissociation With Coral Symbiont Algae. Frontiers in Microbiology, 11, 1791 https://doi.org/10.3389/fmicb.2020.01791

Soneson, C., Love, M. I., \& Robinson, M. D. (2015). Differential analyses for RNA-seq: transcript-level estimates improve gene-level inferences. F1000Res, 4:1521w https://doi.org/10.12688/f1000research.7563.1

Stephens, M. (2017). False discovery rates: a new deal. Biostatistics, 18 275-294

Studivan, M. S., Shatters, A., Dodge, D. L., Beal, J. L., \& Voss, J. D. (2021). Synergistic Effects of Thermal Stress and Estuarine Discharge on Transcriptomic Variation of Montastraea cavernosa Corals in Southeast Florida. Frontiers in Marine Science, 8, 446 https://doi. org/10.3389/fmars.2021.662220

Terraneo, T. I., Fusi, M., Hume, B. C. C. et al (2019). Environmental latitudinal gradients and host-specificity shape Symbiodiniaceae distribution in Red Sea Porites corals. Journal of Biogeography, 46 , 2323-2335

Thomas, L., Rose, N. H., Bay, R. A. et al (2018). Mechanisms of Thermal Tolerance in Reef-Building Corals across a Fine-Grained Environmental Mosaic: Lessons from Ofu. American Samoa. Frontiers in Marine Science, 4, 434 https://doi.org/10.3389/ fmars.2017.00434

Voolstra, C. R., Buitrago-López, C., Perna, G. et al (2020). Standardized short-term acute heat stress assays resolve historical differences in coral thermotolerance across microhabitat reef sites. Global Change Biology, 1, 2015

Voolstra, C. R., Li, Y., Liew, Y. J. et al (2017). Comparative analysis of the genomes of Stylophora pistillata and Acropora digitifera provides evidence for extensive differences between species of corals. 
Scientific Reports, 7, 17583 https://doi.org/10.1038/s41598-01717484-x

Voolstra, C. R., \& Ziegler, M. (2020) Adapting with Microbial Help: Microbiome Flexibility Facilitates Rapid Responses to Environmental Change. BioEssays news and reviews in molecular, cellular and developmental biology, 42, e2000004

Whitley, D., Goldberg, S. P., \& Jordan, W. D. (1999). Heat shock proteins: a review of the molecular chaperones. Journal of Vascular Surgery, 29, 748-751 https://doi.org/10.1016/S0741-5214(99)70329-0

Wickham, H. (2011). ggplot2. Wiley Interdisciplinary Reviews: Computational Statistics, 3, 180-185 https://doi.org/10.1002/ wics.147

Ziegler, M., Arif, C., Burt, J. A. et al (2017). Biogeography and molecular diversity of coral symbionts in the genus Symbiodinium around the Arabian Peninsula. Journal of Biogeography, 44, 674-686

Ziegler, M., Grupstra, C. G. B., Barreto, M. M. et al (2019). Coral bacterial community structure responds to environmental change in a host-specific manner. Nature Communications, 10, 3092 https://doi. org/10.1038/s41467-019-10969-5

Ziegler, M., Roik, A., Röthig, T. et al (2019). Ecophysiology of ReefBuilding Corals in the Red Sea. In C. R. Voolstra, \& M. L. Berumen (Eds.), Coral Reefs of the Red Sea (pp. 33-52). Springer International Publishing
Ziegler, M., Seneca, F. O., Yum, L. K., Palumbi, S. R., \& Voolstra, C. R. (2017). Bacterial community dynamics are linked to patterns of coral heat tolerance. Nature Communications, 8, 14213 https://doi. org/10.1038/ncomms14213

\section{SUPPORTING INFORMATION}

Additional supporting information may be found online in the Supporting Information section.

How to cite this article: Voolstra, C. R., Valenzuela, J. J., Turkarslan, S., Cardenas, A., Hume, B. C. C., Perna, G., Buitrago-Lopez, C., Rowe, K., Orellana, M. V., Baliga, N. S., Paranjape, S., Banc-Prandi, G., Bellworthy, J., Fine, M., Frias-Torres, S., \& Barshis, D. J. (2021). Contrasting heat stress response patterns of coral holobionts across the Red Sea suggest distinct mechanisms of thermal tolerance. Molecular Ecology, 00, 1-15. https://doi.org/10.1111/mec.16064 